\title{
Factors associated with hospitalization after self-poisoning in France: special focus on the impact of alcohol use disorder
}

\author{
Juliette Salles ${ }^{1,2,3^{*}}$ D, Julie Calonge ${ }^{1}$, Nicolas Franchitto ${ }^{1,3}$, Emmanuelle Bougon ${ }^{1,2}$ and Laurent Schmitt ${ }^{1,2}$
}

\begin{abstract}
Background: Previous studies have identified factors associated with admission to hospital after suicide spectrum behaviors. In this study, we aim to identify specific factors associated with psychiatric hospitalization after selfpoisoning. Given earlier findings suggesting that alcohol use disorder is not associated with hospital admission, we also aim to consider its impact, as well as blood alcohol concentrations, on hospitalization decisions after a suicide attempt.

Methods: We studied the association between demographic features, suicide intent, psychiatric characteristics and admission to hospital in self-poisoning patients in an emergency department in France.

Results: Suicide intent, a past history of suicide attempts, bipolar disorder and depression were associated with psychiatric hospital admissions. Despite alcohol use disorder being known to be associated with a suicide risk, it was not linked with psychiatric hospitalization. A positive blood alcohol concentration in the emergency department likewise had no association with admission to a psychiatric ward for inpatient care.

Conclusions: Our findings were similar to those reported for other suicide spectrum behaviors. Alcohol use disorder was not associated with admission for inpatient psychiatric care, whereas depression clearly was. The cause of this discrepancy must be determined in future research.
\end{abstract}

Keywords: Suicide, Epidemiology, Hospitalization, Alcohol use disorder

\section{Background}

Suicide is a major global public health concern and in Europe represents $1.5 \%$ of all deaths [1]. The causes of suicide are multiple and complex and can be linked to psychological, environmental and cultural factors. Among the psychological factors, mental illnesses such as mood disorders, schizophrenia, anxiety disorders, post-traumatic stress and substance abuse [2-6] play an important role and must be regarded as specific suicide risk factors.

In terms of suicide care, $80 \%$ of patients receiving medical help after a suicide attempt are admitted to the emergency ward. In France, every patient hospitalized for an attempted suicide benefits from a psychiatric assessment [7]. This assessment is an opportunity to evaluate the

\footnotetext{
* Correspondence: juliette.salles@hotmail.fr

${ }^{1}$ Université de Toulouse III, F-31000 Toulouse, France

${ }^{2} \mathrm{CHU}$ Toulouse, Service de Psychiatrie eSt Psychologie, Psychiatrie, F-31000

Toulouse, France

Full list of author information is available at the end of the article
}

suicide risk, initiate treatment if required and prevent future self-harm. The assessment of suicide spectrum behaviors in the emergency department is a key factor in preventing suicide [8]. The suicidal patient may be discharged or hospitalized based on the assessment. There are many guidelines on how suicide assessments should be conducted, but none are universally accepted [9-11]. The referral of patients for hospitalization or discharge is a crucial clinical decision, and most guidelines recommend that direct discharge from the emergency department should be considered if an after-care plan can be arranged before the patient leaves hospital. In France, attempted suicide by self-poisoning represents $81.7 \%$ of all suicide attempts. Overall, $66 \%$ of self-poisoned patients are women versus $63 \%$ for the entire population of suicide attempters versus $45 \%$ for other methods. The frequency of self-poisoning versus other suicide methods decreases with age [12]. Compared with other methods, previous 
studies have found that patients who self-poison are less often psychotic and more often have an anxiety or affective disorder than those admitted following the use of violent methods such as hanging, cutting, jumping, and the use of firearms. However, no differences in demographic characteristics (age, marital status, living conditions, educational status and employment status) and a past history of suicide attempts have been identified [13].

Hospitalization is recommended if there is an imminent risk of suicide. Admission policies for suicide treatment have been associated with clinical and psychological factors such as older age, male gender, poor physical health, psychosis, high suicidal intent, a plan to use a lethal method, previous psychiatric hospitalization, a past history of suicide attempts and a low expectation of being found after an attempt $[8,14]$. Hospitalization is generally indicated if the attempt was violent or premeditated, precautions were taken to avoid rescue, distress is increased, the patient regrets surviving, the patient has limited social support, there is current impulsive behavior or a refusal of help is evident, and the patient has a change in mental status with a metabolic, toxic, infectious or other etiology requiring further workup in a structured setting. However, when considering hospitalization, the risk of suicide is not the only factor to take into account, as admission to hospital could reinforce dependency and regressive behaviors. Psychiatric inpatients and their relatives may also have unrealistic expectations and hospitalization can be associated with disillusionment and may contribute to feelings of hopelessness. Moreover, in cases of personality disorder, it may lead to a vicious circle of intensifying suicidal thoughts that require more restrictive care [15].

Within psychiatric disorders, alcohol use disorder (AUD) is particularly associated with an increased suicide mortality rate, which is six times higher than in the general population [16]. A literature review put the suicide risk over a lifetime at $3.4 \%$ in AUD populations in the USA [17], while a meta-analysis found a strong association between suicide attempts and alcohol consumption $(\mathrm{OR}=3.1)$ [18].

Despite the impact that acute alcohol consumption has on decision making, AUD appears to not be related to clinicians' decisions to hospitalize, even though the association between AUD and suicide is largely documented. Indeed, one study [19] specifically addressed the issue of clinical decision-making with respect to hospitalization in a population of patients demonstrating suicide spectrum behaviors, including suicidal ideation, non-suicidal injuries and suicide attempts. This research found that AUD was not associated with admission for inpatient psychiatric care, whereas schizophrenia and depression were. The authors hypothesized that clinicians' decisions about hospitalization could be more related to drug or alcohol consumption associated with suicide attempts than to AUD [20].

Previous data on factors associated with hospital admissions are available for suicide spectrum behaviors, especially in Spain $[8,19]$. However, there is a difference between countries concerning care management, which is why we sought to replicate those results in France. In particular, we aimed to identify factors associated with psychiatric hospitalization, especially in a population of self-poisoning suicide attempters. Regarding previous results, we also aimed to pay specific attention to the impact of AUD and blood alcohol concentrations (BAC) on clinicians' decisions concerning hospitalization.

\section{Methods \\ Participants}

The study took place in Toulouse University Hospital, which is located in the south of France. This hospital benefits from an emergency room that is specifically set up to deal with self-poisoning patients. This ward is a medical department directed by an emergency team in which a psychiatric liaison team ensures that appropriate psychiatric assessments are carried out. This team consists of a nurse and a psychiatrist working 7 days a week, $24 \mathrm{~h}$ a day. All patients who attempt suicide by self-poisoning are referred to this unit.

The WHO definition of a suicide attempt was used, namely: any "act with a non-fatal outcome, in which an individual deliberately initiates a non-habitual behavior that without intervention from others will cause self-harm or deliberately ingests a substance in excess of the prescribed or generally recognized therapeutic dosage" [21].

This article is based on data initially collected between November 2016 and April 2017 for an Intent of Suicide and Alcohol (ISA) study. Patients were excluded if they were under 18 years old, because of the legal liability for research participation. Patients with a diagnosis of mild or severe mental disability and mild or severe neurocognitive impairment were also excluded to ensure the quality of responses. We used administrative data to compare included attempters versus non-included attempters. During the relevant period, 98 patients did not meet the inclusion criteria. In total, 519 patients were recruited, but three were excluded because of incomplete data (Fig. 1).

\section{Measurements}

The data collected included patients' sociodemographic and clinical features, personal and familial history of suicide attempts and type of follow-up (inpatient or outpatient care). 


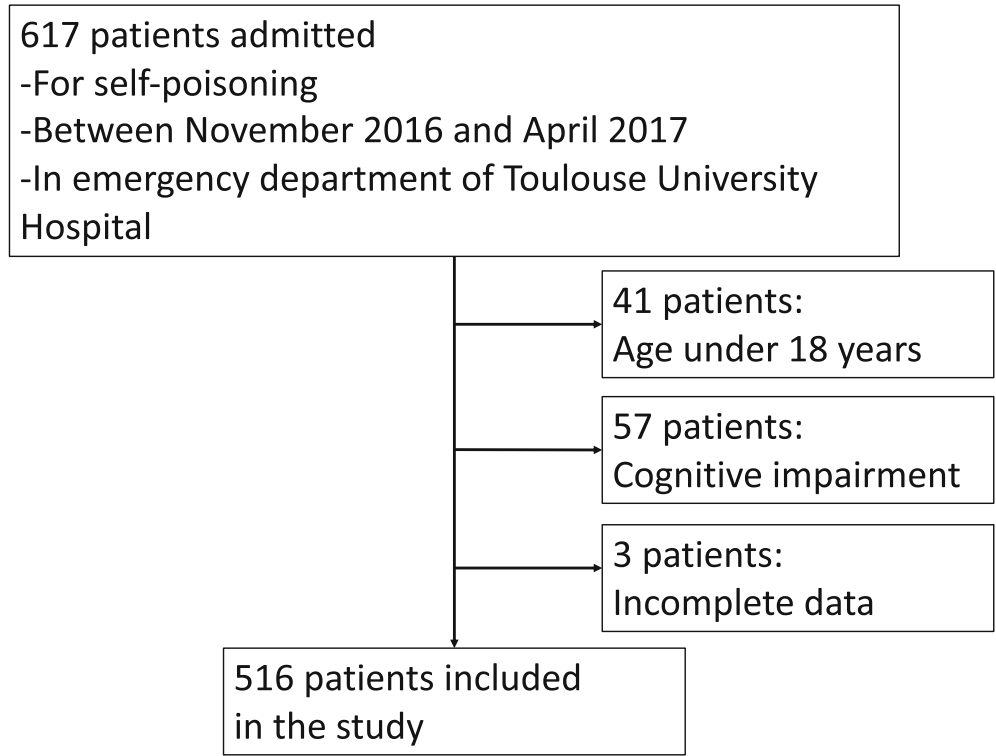

Fig. 1 Flow chart

Sociodemographic characteristics consisted of age, gender, living status (alone or not) and employment status.

Clinical features comprised psychiatric diagnoses according to the DSM IV criteria, which were assessed by referring to the Mini International Neuropsychiatry Interview (MINI) subset (A-I) [22].

Data on prior mental health-care included previous psychiatric follow-up by a psychiatrist, a history of suicide attempts and a personality disorder diagnosis. This data was collected from the information in patient assessments or the emergency database concerning previous medical involvement.

Data concerning suicide attempts included information obtained from the Intent of Suicide Assessment, which is based on the Pierce Scale [23]. The Pierce Scale is a 12-item questionnaire designed to assess the severity of suicide intent associated with an episode of self-harm. Each item scores $0-3$, giving a total score of $0-25$. The questionnaire is divided into three sections: the first six items constitute the "circumstances" section and are concerned with the objective circumstances of the act of self-harm; the following four items constitute the "self-report" section and are based on patients' own reconstructions of their feelings and thoughts at the time of the act; finally the remaining two items constitute the "risk" section and are concerned with the medical risk of self-harm relative to the lethality of the suicide method.

Blood samples were taken systematically at the time of admission to the emergency unit in order to determine blood alcohol concentrations (BACs).
Referrals were separated into two pathways:

-Outpatient psychiatric care: this consisted of an at-home psychiatric appointment with a primary psychiatrist, information to make an appointment with a psychiatrist in public medical psychological centers (CMPs) or an appointment with a psychiatrist in a brief therapy center (CTB).

-Inpatient psychiatric care: this consisted of either voluntary or forced hospitalization in a psychiatric department.

The psychiatric assessments were performed in an emergency ward that enabled all patients to be evaluated, including those who were severely intoxicated. Evaluations were performed after cognitive assessments and negative BACs were obtained to ensure that patients were capable of being assessed.

Referrals were systematically determined by a psychiatrist during a psychiatric assessment.

We also collected data relating to repeat suicide attempts at 1 year from the administrative database of Toulouse University's emergency department.

\section{Data analysis}

We compared sociodemographic characteristics and clinical features according to the referral after the psychiatric assessment. Quantitative variables are described using the mean $(+/-$ standard deviation) and/or median (+/- interquartile range) according to their distributions.

The Shapiro-Wilk test was performed to evaluate the normality distribution of the data. In cases of non-normal 
data, the Wilcoxon non-parametric test was applied; the Student $\mathrm{T}$ test was used for normal data. Associations between qualitative variables were tested using the chi-squared or the Fischer test (when expected values were less than five). Statistical significance was set at $p<$ 0.05 . Multinomial logistic regression was used to assess the association between clinical features (past history of suicide, depression, schizophrenia, bipolar disorder, AUD, personality disorder, suicide intent, BACs), sociodemographic characteristics (age, gender, living status: alone or not, living status: housed or not, and professional status: employed or not), and the outcome of being referred for psychiatric hospitalization or psychiatric outpatient care. We used a logistic analysis to identify variables independently associated with the referrals [24]. We then performed backward stepwise analyses to achieve our final model. Statistical significance was set at $p<0.05$. We tested the interactions between all the variables included in the final model.

The statistical analyses were performed using the R-Studio software, version 14R (StataCorp LP, College Station, TX, USA).

\section{Results}

\section{Sample description}

A total of 165 men (31.9\%) and 351 women (68.1\%) were included in the sample. The mean age was $40.5(\mathrm{SD}=$ $14.8)$ and the median age $42(\mathrm{IQ}=27-51)$. Overall, during self-poisoning, $38.58 \%$ of patients ingested two medications, $10.85 \%$ ingested three and $1.16 \%$ ingested more than three. The most common medications used were benzodiazepines, with $85 \%$ of patients ingesting at least one of these. Paracetamol accounted for $8.91 \%$ of the ingested drugs and opioids $3.68 \%$. The characteristics of the overall sample are described in Table 1.

Most of the patients did not live alone (65.1\%), 38.0\% were employed and $92.0 \%$ had a home. More than half of the patients had a history of suicide attempts (59.7\%) and $17.8 \%$ had a family history of suicide. In our sample, according to the DSM IV criteria, the AUD prevalence was $30.0 \%$, the mood disorder prevalence $44.0 \%$, including $33.0 \%$ with depression and $11.0 \%$ with bipolar disorder, and the schizophrenia prevalence was 3\%. Thirty-four percent of patients had a previous diagnosis of a personality disorder, mostly borderline personality (58.2\%).

After psychiatric assessment, $32.9 \%$ of patients were referred for inpatient psychiatric care and $67.1 \%$ to outpatient care. Compulsory inpatient admissions comprised $9 \%$ of the total admissions.

The repeat suicide attempt rate within the one-year follow-up period was 25.51\%: $24.69 \%$ for inpatient care and $28.10 \%$ for outpatient care. Patients suffering from AUD had a higher rate of repetition of $38 \%$, versus $24 \%$ in the non-AUD group. In patients with personality disorders, the repetition rate in this sub-group was similar between those with or without AUD: respectively 34.53\% and $36.0 \%$. When they were referred for inpatient care, patients with a personality disorder and AUD made fewer repeat suicide attempts than those without AUD: respectively $16.66 \%$ versus $42.10 \%$. Adjusting for the Pierce score and sociodemographic factors, we found that in the non-AUD group inpatient orientation reduced the rate of repeat attempts by $2 \%$ at 1 year compared to outpatient care. Moreover, in the AUD group, inpatient care reduced the rate of repeat attempts by $5 \%$ at 1 year compared to outpatient care.

\section{Factors associated with referral for psychiatric hospitalization}

Table 2 presents the characteristics associated with inpatient psychiatric care determined by univariate and multivariate analyses. We chose to include variables previously associated with a suicide risk in the model.

In the univariate analysis, age $(p \leq 0.001)$ and depression $(p \leq 0.001)$ were significantly associated with psychiatric hospitalization, whereas personality disorder $(p \leq 0.001)$ was associated with outpatient care.

In the multivariate analysis, compared to those who had no depression, those who were depressed were more often hospitalized in the psychiatric department $(\mathrm{OR}=3.6,95 \%$ $\mathrm{CI}=2.18-6.05)$. Bipolar disorder $(\mathrm{OR}=3.16 ; 1.57-6.33)$, a history of suicide attempts $(\mathrm{OR}=1.53 ; 0.95-2.47)$ and suicide intent $(\mathrm{OR}=1.18 ; 0.13-1.24)$ were also associated with a higher rate of hospitalization.

The association of a personality disorder or schizophrenia with hospitalization was not significant.

Although AUD was significantly related to a suicide risk, patients suffering from the condition did not have a higher likelihood of being referred to inpatient care (OR $=0.87 ; 0.49-1.54)(p=0.65)$. BACs were also not associated with a clinician's decision to hospitalize a patient $(\mathrm{OR}=0.87 ; 0.64-1.18),(p=0.39)$ (Fig. 1).

As the presence of a personality disorder often affected the referral decision, we performed a regression analysis on patients that excluded this as a variable. The results were similar to those observed in the overall sample. Indeed, we noted that depressive episodes $(\mathrm{OR}=3.58,95 \%$ $\mathrm{CI}=1.93-6.80)(p<0.001)$, bipolar disorder $(\mathrm{OR}=2.36$, $95 \% \mathrm{CI}=1.02-5.44)(p=0.04)$, the Pierce score $(\mathrm{OR}=$ $1.17,95 \% \mathrm{CI}=1.11-1.23)(p<0.001)$ and housing status $(\mathrm{OR}=3.21,95 \% \mathrm{CI}=1.87-16.97)(p<0.001)$ were associated with inpatient referrals Fig. 2.

\section{Discussion}

The main finding of our study was that AUD was not associated with psychiatric admissions. This also underlined a discrepancy in the consideration of AUD and 
Table 1 Descriptive characteristics of the study population

\begin{tabular}{|c|c|c|}
\hline & $\mathrm{N}$ & $\%$ \\
\hline \multicolumn{3}{|l|}{ Age } \\
\hline $18-39$ years & 233 & 45.16 \\
\hline 40-59 years & 242 & 46.90 \\
\hline more than 60 years & 41 & 7.95 \\
\hline \multicolumn{3}{|l|}{ Gender } \\
\hline Men & 165 & 31.98 \\
\hline Women & 351 & 68.02 \\
\hline \multicolumn{3}{|l|}{ Number of medication used } \\
\hline One & 516 & 100 \\
\hline Two & 199 & 38.56 \\
\hline Three & 56 & 10.85 \\
\hline More than three & 6 & 1.16 \\
\hline \multicolumn{3}{|l|}{ Type of drug used } \\
\hline Benzodiazepine & 439 & 85 \\
\hline Paracetamol & 46 & 8.91 \\
\hline Non-steroidal anti-inflammatory Drugs & 25 & 4.84 \\
\hline Neuroleptic & 46 & 8.91 \\
\hline Antidepressant & 26 & 5.03 \\
\hline Opioids & 19 & 3.68 \\
\hline Others & 35 & 6.78 \\
\hline Not known & 10 & 1.93 \\
\hline Past history of suicide & 308 & 59.69 \\
\hline Family past history of suicide & 92 & 17.83 \\
\hline Psychiatric disorder & 351 & 68.02 \\
\hline Depression & 170 & 32.95 \\
\hline Schizophrenia & 18 & 3.49 \\
\hline Bipolar disorder & 59 & 11.43 \\
\hline Alcohol use disorder (AUD) & 155 & 30.04 \\
\hline AUD and depression & 54 & 34.83 \\
\hline AUD and bipolar disorder & 13 & 8.38 \\
\hline AUD and schizophrenia & 4 & 2.58 \\
\hline AUD and personality disorder & 65 & 41.93 \\
\hline Borderline & 23 & 14.83 \\
\hline Dependent & 31 & 20.00 \\
\hline Avoiding & 2 & 1.29 \\
\hline Histrionic & 1 & 0.64 \\
\hline Narcissistic & 1 & 0.64 \\
\hline Obsessive & 1 & 0.64 \\
\hline Antisocial & 6 & 3.87 \\
\hline Personality disorder & 178 & 34.50 \\
\hline Borderline & 104 & 20.16 \\
\hline Dependent & 45 & 8.72 \\
\hline Avoiding & 1 & 0.19 \\
\hline Histrionic & 6 & 1.16 \\
\hline
\end{tabular}

Table 1 Descriptive characteristics of the study population (Continued)

\begin{tabular}{lll}
\hline & $\mathrm{N}$ & $\%$ \\
\hline Narcissistic & 3 & 0.58 \\
Obsessive & 2 & 0.39 \\
Antisocial & 17 & 3.29 \\
Single & 179 & 34.69 \\
Employed & 198 & 38.37 \\
Housing & 474 & 91.86 \\
\hline
\end{tabular}

other psychiatric diagnoses such as depression and bipolar disorders, which were associated with more inpatient referrals.

\section{Admission rate}

The total admission rate of $32.9 \%$ in our sample is higher than that previously described in Spain (26.8\%) [19] or Finland (24\%) [25], but is lower than the rate in Switzerland, England or the WHO/Euro Multicentre Study on Parasuicide, in which almost half of patients were admitted for inpatient care after a suicide attempt [9, $26,27]$.Those differences in hospitalization rates could be explained by differences in patient characteristics, care organizations and clinical practices.

\section{Factors associated with psychiatric hospitalization}

Depression was the main predictive factor of psychiatric inpatient care. Depression is also the most common psychiatric disorder in suicide attempters $[28,29]$. This was also the case in our study, with it accounting for $48 \%$ of all psychiatric diagnoses. Bipolar disorder was independently associated with increased hospitalization. This is unsurprising, as it is known to be associated with suicide attempts or death by suicide [30]. Contrary to a previous study [19], schizophrenia and personality disorder were not associated with psychiatric inpatient care in our sample. In relation to the former, this could be due to the small representation (only $3 \%$ of patients) of this diagnosis in our study.

In our sample, $20.16 \%$ of patients suffered from a borderline personality disorder. This is relevant because, personality disorders, especially borderline personality, are commonly observed among individuals who attempt suicide. We found no association between personality disorder and inpatient referral. This could be explained by the fact that the role of hospitalization after suicide attempts has generated controversy. One group advocates that hospitals keep patients safe and are appropriate for the treatment of co-morbidities, diagnosis clarifications and simplifying prescription medications $[31,32]$. Others point out that minimal evidence exists concerning the efficacy of hospitalization for chronic suicidality. Moreover, hospitalization can result in 
Table 2 Characteristics associated with psychiatric hospitalization

\begin{tabular}{|c|c|c|c|c|c|}
\hline & \multicolumn{5}{|c|}{ Hospitalization } \\
\hline & \multicolumn{2}{|c|}{ Univariate comparison } & \multirow[b]{2}{*}{$p$} & \multirow{2}{*}{$\begin{array}{l}\text { Multivariate logistic regression } \\
\text { OR [95\%IC] }\end{array}$} & \multirow[b]{2}{*}{$p$} \\
\hline & Yes $(n=162)$ & $\mathrm{No}(n=354)$ & & & \\
\hline \multicolumn{6}{|l|}{ Sociodemographics } \\
\hline Age (years) & 43.9 & 38.8 & $<0.001$ & $1.01[0.99-1.02]$ & 0.12 \\
\hline $\begin{array}{l}\text { Gender } \\
\text { Men }(n=165)\end{array}$ & $48(29.6)$ & $117(33)$ & 0.65 & $0.91[0.55-1.53]$ & 0.74 \\
\hline $\begin{array}{l}\text { Living status ( } n=474) \\
\text { Housing or not }\end{array}$ & $155(95.6)$ & $319(90.1)$ & 0.69 & $1.16[0.45-3.38]$ & 0.76 \\
\hline $\begin{array}{l}\text { Living status ( } n=179) \\
\text { Alone or not }\end{array}$ & $58(35.8)$ & $121(34.1)$ & 0.85 & $1.23[0.77-1.98]$ & 0.37 \\
\hline $\begin{array}{l}\text { Professional status ( } n=198 \text { ) } \\
\text { Employee or not }\end{array}$ & $68(41.9)$ & $130(36.7)$ & 0.49 & $1.25[0.78-2.01]$ & 0.34 \\
\hline \multicolumn{6}{|l|}{ Psychopathology and care characteristics } \\
\hline Depression $(n=170)$ & $89(54.9)$ & $81(22.8)$ & $<0.001$ & $3.6[2.18-6.05]$ & $<0.001$ \\
\hline Schizophrenia $(n=18)$ & $5(3.1)$ & $13(3.7)$ & 0.95 & $1.63[0.43-5.4]$ & 0.43 \\
\hline Bipolar disorder $(n=59)$ & $23(14.2)$ & $36(10.1)$ & 0.29 & 3.16 [1.57-6.33] & $<0.001$ \\
\hline Alcohol use disorder $(n=155)$ & $43(26.5)$ & $112(31.6)$ & 0.45 & $0.87[0.49-1.54]$ & 0.65 \\
\hline Personality disorder( $n=178)$ & $29(17.9)$ & $150(42.3)$ & $<0.001$ & $1.03[0.62-1.71]$ & 0.89 \\
\hline Suicidal intentionnality (Pierce Score) & $9.8(5.7)$ & $4.5(4.4)$ & $<0.001$ & $1.18[1.13-1.24]$ & $<0.001$ \\
\hline Past history of suicide ( $n=308$ ) & $107(66.1)$ & $201(59.3)$ & 0.34 & $1.53[0.95-2.47]$ & 0.07 \\
\hline Blood alcohol concentration (BAC) mean (SD) & $0.63(0.93)$ & $0.62(0.92)$ & 0.11 & $0.87[0.64-1.18]$ & 0.39 \\
\hline
\end{tabular}

negative consequences for patients with a borderline personality, including behavioral regression [33].

In terms of the data regarding suicide characteristics, and in parallel with the results of [8], we found that a previous suicide attempt was associated with impatient care, as was suicidal intent.

Surprisingly, we found no association with sociodemographic characteristics, despite previous studies finding a link between male gender and psychiatric inpatient care. One explanation could be a recruitment bias among suicide attempters, as we only recruited the self-poisoning population, which comprised a large majority of women (68\%). However, the careful evaluation of other important clinical variables (suicide intent, psychiatric disorder and sociodemographic) has tempered the gender effect.

BACs were not associated with inpatient orientation, which is probably explained by the fact that the patient assessment is only performed when the estimated BAC is below $0.05 \mathrm{~g} / \mathrm{L}$.

AUD is also a well-recognized suicide risk factor, but was not associated with psychiatric inpatient care decisions in our sample. We also found no association between BACs and the decision to hospitalize.

This finding underlines the fact that, in our center, AUD is considered differently to depression in clinician decisions, whereas previous studies found a similar suicidal risk increase with a depression or AUD diagnosis (respectively $\mathrm{OR}=2.2$ and $\mathrm{OR}=2.4$ ) [34]. Since the decision to treat a suicide attempter as an outpatient is often due to these diagnoses, we performed an analysis on the sample excluding personality disorders and achieved a similar result to that for the entire population. This tends to confirm that AUD is considered differently to depression, even if patients do not suffer from a personality disorder.

Comparing patients with depression and co-morbid AUD, we found that they were less often referred for inpatient care than non-AUD patients $(46.4 \%$ versus $53.5 \%)$.

Moreover, care referrals depended on the level of the risk of repetition, and AUD is related to multiple suicide attempts $[35,36]$ and rapid reattempts, as $50 \%$ of patients plan their suicide attempt less than 1 week before it takes place [37-39], although unplanned suicide attempts can still be deadly [40]. In addition, alcohol intoxication could promote a suicide attempt because of its disinhibitory effect $[38,39]$, and patients with AUD are at risk of alcohol consumption, including after a suicide attempt.

A longer period of follow-up is the most protective factor when it comes to preventing another suicide attempt [41], which is why, in practice, a psychiatric evaluation needs to assess the effectiveness of outpatient care. Inpatient care after a suicide attempt does not lead to any reduction in the long-term suicide rate compared to outpatient care; in fact, the main protective factors 


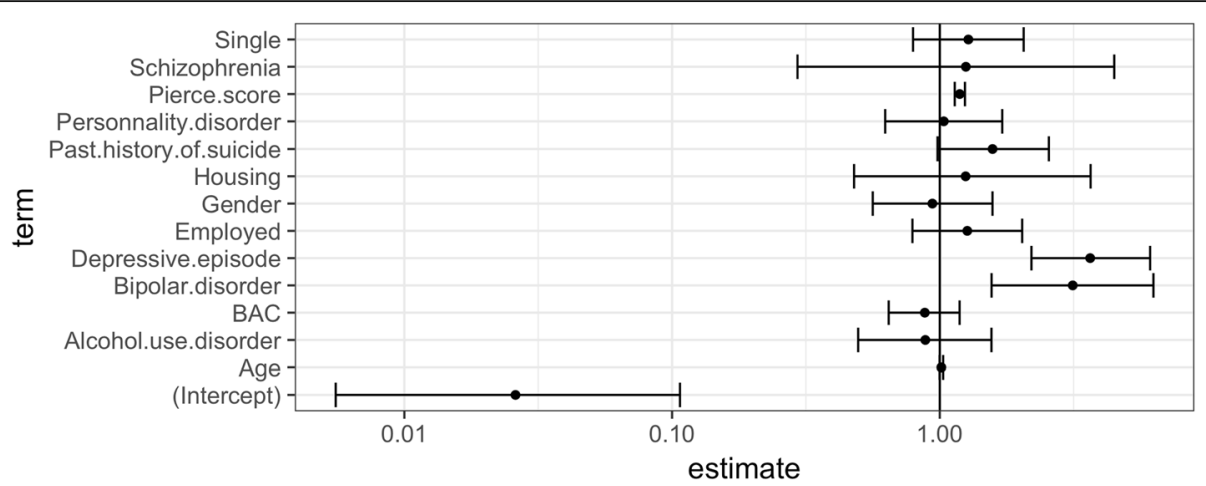

Fig. 2 Factors associated with hospitalization. The figure represents the OR as an estimate. On the $x$-axis part of the figure, the left of the $y$-axis represents outpatient care and the right part inpatient care

consist of a care program independent of inpatient or outpatient modalities [28, 42, 43]. However, it has been shown that patients suffering from substance abuse, including AUD, have difficulty engaging in outpatient care $[44,45]$. This could therefore mean that inpatient care should be specifically considered during a suicide crisis in order to place the patient at a distance from alcohol, thereby reducing impulsivity, improving mood and promoting follow-up observance [46, 47].

In our database, we found that patients with AUD had a higher risk of repetition than those without AUD. We also found that outpatient care reduced the repetition rate at 1 year in the AUD versus the non-AUD population. This result also led to consideration of inpatient referrals in this group. However, the study was not designed to evaluate repetition rates and we therefore only report retrospective descriptive data concerning the evolution at 1 year. This finding must therefore be confirmed by future studies that specifically focus on this issue.

The discrepancy between the impact of AUD and depression on clinician decisions also needs to be addressed. It could partly be explained by the stigmatization of patients with AUD. Indeed, AUD is the most judged behavior compared with other health conditions such as obesity, depression or schizophrenia [48]. Previous studies reported in the literature demonstrated that AUD was less commonly regarded as a mental illness than depression or schizophrenia [49]. Nevertheless, a previous study showed that holding a conception of AUD as a mental illness increased treatment access [50]. In addition, a study including internal medicine residents found a lower regard for AUD patients than those with other common conditions [51]. Further, previous data suggest that patients hospitalized for suicide risk who are judged to have a risk related to alcohol intoxication are discharged sooner than those who are not perceived to have a substance-related risk [52]. This knowledge led to consideration of whether AUD is stigmatized and its implications for a clinician's decision-making, including by psychiatrists, when it comes to treating suicide attempters. In our study, it is possible to hypothesize that different views of AUD and other psychiatric disorders could partly lead to care discrimination through a clinician's decision not to associate AUD with admission to hospital.

A limitation of this study is that we did not take the types of care for other addictions into account. Other addictions are reported on less, suggesting that practitioners do not consider them when deciding the type of care that a patient requires. Another limitation is that this was a single center study and, despite this center evaluating patients using international guidelines, our observations could not be generalized to all patients seen in France after a self-poisoning suicide attempt. Despite self-poisoning accounting for $82 \%$ of suicide attempts in France, this population is very specific. For example, other groups, such as those who attempt suicide by hanging or the use of firearms, are mostly represented by men and are suicide methods associated with greater lethality. Moreover, previous studies have referred to heterogeneity in a population with AUD that is explained by different settings and different populations, leading us to emphasize that our findings are limited to patients with AUD who attempted suicide by self-poisoning [33]. Another limitation is the study's cross-sectional design, which does not enable us to argue that there is a causal relationship. Despite these limitations, the strength of the study is the exhaustiveness of the data, as all eligible patients (expect for three) admitted during the study period were systematically screened. Well-designed intervention studies are now needed to better characterize the possible implications of AUD stigmatization after a suicide attempt and to provide effective strategies to improve AUD consideration in self-poisoning patients.

\section{Conclusion}

Our study confirms previous data, which underline the lack of consideration of AUD co-morbidity in suicide 
attempters. It also underlines differences in how the condition is considered compared to depression, even though both psychiatric disorders are associated with a similar increased risk of suicide. Moreover, there are specific concerns about the efficacy of outpatient care for AUD patients, given that the AUD population is known to be less compliant with outpatient appointments. In the context of a need to prevent repeat suicide attempts, our results demonstrate that the issue of AUD and suicide must be specifically addressed.

\section{Funding}

This research did not receive any specific funding from agencies in the public, commercial, or not-for-profit sectors.

\section{Availability of data and materials}

The datasets used and/or analysed during the current study are available from the corresponding author on reasonable request.

\section{Authors' contributions}

JS and LS initiated the study. JS, JC and EB recruited the participants. JS and JC contributed to the analysis. JS, JC, EB and NF were involved in writing the publication.

\section{Ethics approval and consent to participate}

All procedures followed were in accordance with the ethical standards of the responsible committee on human experimentation (institutional and national) and with the Helsinki Declaration of 1975, as revised in 2000 (5). All participants provided written informed consent.

The study was approved by the Committee for the Protection of Persons, No. ID-RCB: 2017-A00641-52.

\section{Consent for publication}

Not applicable

\section{Competing interests}

The authors declare that they have no competing interests.

\section{Publisher's Note}

Springer Nature remains neutral with regard to jurisdictional claims in published maps and institutional affiliations.

\section{Author details}

${ }^{1}$ Université de Toulouse III, F-31000 Toulouse, France. ${ }^{2} \mathrm{CHU}$ Toulouse, Service de Psychiatrie eSt Psychologie, Psychiatrie, F-31000 Toulouse, France. ${ }^{3} \mathrm{CHU}$ Toulouse, Service d'addictologie clinique, urgences réanimation médecine, F-31000 Toulouse, France.

Received: 16 May 2018 Accepted: 16 August 2018

Published online: 06 September 2018

\section{References}

1. Murray CJL, Lopez AD. Measuring the global burden of disease. N Engl J Med. 2013;369:448-57.

2. Kessler RC, Borges G, Walters EE. Prevalence of and risk factors for lifetime suicide attempts in the National Comorbidity Survey. Arch Gen Psychiatry. 1999;56:617-26.

3. Kuo WH, Gallo JJ, Tien AY. Incidence of suicide ideation and attempts in adults: the 13-year follow-up of a community sample in Baltimore. Maryland Psychol Med. 2001;31:1181-91.

4. Kelly TM, Cornelius JR, Clark DB. Psychiatric disorders and attempted suicide among adolescents with substance use disorders. Drug Alcohol Depend. 2004;73:87-97.

5. Bernal M, Haro JM, Bernert S, Brugha T, de Graaf R, Bruffaerts R, et al. Risk factors for suicidality in Europe: results from the ESEMED study. J Affect Disord. 2007;101:27-34
6. Sareen J, Houlahan T, Cox BJ, Asmundson GJG. Anxiety disorders associated with suicidal ideation and suicide attempts in the National Comorbidity Survey. J Nerv Ment Dis. 2005;193:450-4.

7. Haute Autorité de Santé - La crise suicidaire: reconnaître et prendre en charge. [cité 11 avr 2018]. Disponible sur: https://www.has-sante.fr/portail/ jcms/c_271964/fr/la-crise-suicidaire-reconnaitre-et-prendre-en-charge

8. Baca-García E, Diaz-Sastre C, Resa EG, Blasco H, Conesa DB, Saiz-Ruiz J, et al. Variables associated with hospitalization decisions by emergency psychiatrists after a patient's suicide attempt. Psychiatr Serv Wash DC. 2004;55:792-7.

9. Bennewith O, Gunnell D, Peters T, Hawton K, House A. Variations in the hospital management of self harm in adults in England: observational study. BMJ. 2004;328:1108-9.

10. Hawton K, Bergen H, Casey D, Simkin S, Palmer B, Cooper J, et al. Self-harm in England: a tale of three cities. Multicentre study of self-harm. Soc Psychiatry Psychiatr Epidemiol. 2007:42:513-21.

11. Olfson M, Gameroff MJ, Marcus SC, Greenberg T, Shaffer D. Emergency treatment of young people following deliberate self-harm. Arch Gen Psychiatry. 2005;62:1122-8.

12. Chan CC, \& Jezewski-Serra D. Hospitalisations et recours aux urgences pour tentative de suicide en France métropolitaine à partir du PMSI-MCO 20042011 et d'Oscour ${ }^{\circledast 2}$ 2007-2011. Saint-Maurice: Institut de veille sanitaire. 2014; 25-34.

13. Persett PS, Grimholt TK, Ekeberg O, Jacobsen D, \& Myhren H. Patients admitted to hospital after suicide attempt with violent methods compared to patients with deliberate self-poisoning -a study of background variables, somatic and psychiatric health and suicidal behavior. BMC Psychiatry, 2018; 18(1):21. https://doi.org/10.1186/s12888-018-1602-5.

14. Goldberg JF, Ernst CL, Bird S. Predicting hospitalization versus discharge of suicidal patients presenting to a psychiatric emergency service. Psychiatr Serv. 2007:58:561-5.

15. American Psychiatric Association (APA). Practice guideline for the assessment and treatment of patients with suicidal behaviors. 2010

16. Inskip HM, Harris EC, Barraclough B. Lifetime risk of suicide for affective disorder, alcoholism and schizophrenia. Br J Psychiatry J Ment Sci. 1998;172:35-7.

17. Murphy GE, Wetzel RD. The lifetime risk of suicide in alcoholism. Arch Gen Psychiatry. 1990;47:383-92.

18. Darvishi N, Farhadi M, Haghtalab T, Poorolajal J. Alcohol-Related Risk of Suicidal Ideation, Suicide Attempt, and Completed Suicide: A Meta-Analysis. PLoS ONE. 2015:10. [cité 30 juill 2017] Disponible sur: http://www.ncbi.nlm.nih.gov/pmc/ articles/PMC4439031/

19. Jiménez-Treviño L, Saiz PA, Corcoran P, Burón P, García-Portilla MP, Chinea $E R$, et al. Factors associated with hospitalization after suicide spectrum behaviors: results from a multicenter study in Spain. Arch Suicide Res Off J Int Acad Suicide Res. 2015;19:17-34.

20. Baca-García E, Perez-Rodriguez MM, Basurte-Villamor I, Saiz-Ruiz J, LeivaMurillo JM, de Prado-Cumplido $M$, et al. Using data mining to explore complex clinical decisions: a study of hospitalization after a suicide attempt. J Clin Psychiatry. 2006;67:1124-32.

21. Platt S, Bille-Brahe U, Kerkhof A, Schmidtke A, Bjerke T, Crepet P, et al. Parasuicide in Europe: the WHO/EURO multicentre study on parasuicide. I. Introduction and preliminary analysis for 1989. Acta Psychiatr Scand. 1992; 85:97-104.

22. Sheehan DV, Lecrubier $Y$, Sheehan KH, Amorim P, Janavs J, Weiller E, et al. The Mini-International Neuropsychiatric Interview (M.I.N.I.): the development and validation of a structured diagnostic psychiatric interview for DSM-IV and ICD-10. J Clin Psychiatry. 1998;59(Suppl 20): 22-33. quiz 34-57

23. Pierce DW. Suicidal intent in self-injury. Br J Psychiatry J Ment Sci. 1977;130: 377-85.

24. Barros AJD, \& Hirakata VN. Alternatives for logistic regression in crosssectional studies: an empirical comparison of models that directly estimate the prevalence ratio. BMC Medical Research Methodology. 2003;3:21. https://doi.org/10.1186/1471-2288-3-21.

25. Suominen $\mathrm{K}$, Lönnqvist J. Determinants of psychiatric hospitalization after attempted suicide. Gen Hosp Psychiatry. 2006;28:424-30.

26. Hepp U, Moergeli H, Trier SN, Milos G, Schnyder U. Attempted suicide: factors leading to hospitalization. Can J Psychiatry Rev Can Psychiatr. 2004; 49:736-42.

27. Schmidtke A, Bille-Brahe U, DeLeo D, Kerkhof A, Bjerke T, Crepet P, et al. Attempted suicide in Europe: rates, trends and sociodemographic characteristics of suicide attempters during the period 1989-1992. 
Results of the WHO/EURO multicentre study on Parasuicide. Acta Psychiatr Scand. 1996;93:327-38.

28. Waterhouse J, Platt S. General hospital admission in the management of parasuicide. A randomised controlled trial. Br J Psychiatry J Ment Sci. 1990; 156:236-42.

29. Marquet RL, Bartelds AIM, Kerkhof AJFM, Schellevis FG, van der Zee J. The epidemiology of suicide and attempted suicide in Dutch general practice 1983-2003. BMC Fam Pract. 2005;6:45.

30. Malhi GS, Outhred T, Das P, Morris G, Hamilton A, Mannie Z. Modeling suicide in bipolar disorders. Bipolar Disord. 2018;20(4):334-348.

31. Goodman M, Roiff T, Oakes AH, Paris J. Suicidal risk and management in borderline personality disorder. Curr Psychiatry Rep. 2012;14:79-85.

32. Vijay NR, Links PS. New frontiers in the role of hospitalization for patients with personality disorders. Curr Psychiatry Rep. 2007;9:63-7.

33. Paris J. Is hospitalization useful for suicidal patients with borderline personality disorder? J Personal Disord. 2004;18:240-7.

34. Darvishi N, Farhadi M, Haghtalab T, Poorolajal J. Alcohol-related risk of suicidal ideation, suicide attempt, and completed suicide: a metaanalysis. PLoS One. 2015;10:e0126870.

35. Monnin J, Thiemard E, Vandel P, Nicolier M, Tio G, Courtet $P$, et al. Sociodemographic and psychopathological risk factors in repeated suicide attempts: gender differences in a prospective study. J Affect Disord. 2012:136:35-43.

36. Perquier F, Duroy D, Oudinet C, Maamar A, Choquet C, Casalino E, et al. Suicide attempters examined in a Parisian emergency department: contrasting characteristics associated with multiple suicide attempts or with the motive to die. Psychiatry Res. 2017;253:142-9.

37. Conner KR, Hesselbrock VM, Schuckit MA, Hirsch JK, Knox KL, Meldrum $S$, et al. Precontemplated and impulsive suicide attempts among individuals with alcohol dependence. J Stud Alcohol. 2006;67:95-101.

38. Suokas J, Lönnqvist J. Suicide attempts in which alcohol is involved: a special group in general hospital emergency rooms. Acta Psychiatr Scand. 1995;91:36-40

39. Hufford MR. Alcohol and suicidal behavior. Clin Psychol Rev. 2001;21:797-811.

40. Simon OR, Swann AC, Powell KE, Potter LB, Kresnow MJ, O'Carroll PW. Characteristics of impulsive suicide attempts and attempters. Suicide Life Threat Behav. 2001;32:49-59.

41. Guthrie E, Patton GC, Kapur N, Mackway-Jones K, Chew-Graham C, Moorey $J$, et al. Randomised controlled trial of brief psychological intervention after deliberate self poisoningCommentary: another kind of talk that works? BMJ. 2001;323:135.

42. Bostwick JM, Pankratz VS. Affective disorders and suicide risk: a reexamination. Am J Psychiatry. 2000;157:1925-32.

43. Paris J. Chronic suicidality among patients with borderline personality disorder. Psychiatr Serv. 2002;53:738-42.

44. Simpson DD, Joe GW, Rowan-Szal GA, Greener JM. Drug abuse treatment process components that improve retention. J Subst Abus Treat. 1997;14:565-72.

45. Joe GW, Simpson DD, Broome KM. Retention and patient engagement models for different treatment modalities in DATOS. Drug Alcohol Depend. 1999:57:113-25.

46. Davidson M, Galderisi S, Weiser M, Werbeloff N, Fleischhacker WW, Keefe RS, et al. Cognitive effects of antipsychotic drugs in first-episode schizophrenia and schizophreniform disorder: a randomized, open-label clinical trial (EUFEST). Am J Psychiatry. 2009;166:675-82.

47. Ruusa J, Bergman B, Sundell M-L. Alcohol withdrawal, psychologica symptoms, and treatment success. Subst Abuse. 2000;21:129-35.

48. Ronzani TM, Higgins-Biddle J, Furtado EF. Stigmatization of alcohol and other drug users by primary care providers in Southeast Brazil. Soc Sci Med. 2009;69:1080-4.

49. Link BG, Phelan JC, Bresnahan M, Stueve A, Pescosolido BA. Public conceptions of mental illness: labels, causes, dangerousness, and social distance. Am J Public Health. 1999:89:1328-33.

50. Pescosolido BA, Martin JK, Long JS, Medina TR, Phelan JC, Link BG. « a disease like any other »? A decade of change in public reactions to schizophrenia, depression, and alcohol dependence. Am J Psychiatry. 2010;167:1321-30.

51. Meltzer EC, Suppes A, Burns S, Shuman A, Orfanos A, Sturiano CV, et al. Stigmatization of substance use disorders among internal medicine residents. Subst Abuse. 2013;34:356-62.

52. Ries RK, Yuodelis-Flores C, Comtois KA, Roy-Byrne PP, Russo JE. Substanceinduced suicidal admissions to an acute psychiatric service: characteristics and outcomes. J Subst Abus Treat. 2008;34:72-9.

Ready to submit your research? Choose BMC and benefit from:

- fast, convenient online submission

- thorough peer review by experienced researchers in your field

- rapid publication on acceptance

- support for research data, including large and complex data types

- gold Open Access which fosters wider collaboration and increased citations

- maximum visibility for your research: over $100 \mathrm{M}$ website views per year

At BMC, research is always in progress.

Learn more biomedcentral.com/submissions 